\title{
A Corpus-Based Study on English Synonyms: Babble, Blather, Chatter, Gibber, Jabber and Prattle
}

\author{
Mohammad AlAmro ${ }^{1}$ \\ ${ }^{1}$ English Language Center, Institute of Public Administration, Riyadh, Saudi Arabia \\ Correspondence: Mohammad AlAmro, Riyadh, Saudi Arabia. \\ Email: alamrom@gmail.com
}

Received: July 14, 2019

Accepted: August 23, 2019

Online Published: September 1, 2019

doi: 10.23918/ijsses.v6i1p122

\begin{abstract}
This paper examines in detail the six English words: babble, blather, gibber, jabber, prattle and chatter. While at first glance these words appear to have very similar meanings, and indeed can appear as synonyms of one another, each encompasses a different gradient of meaning. This paper describes the semantic usage and different senses of connotation that belong to these six words and also examines the lexical category of the word and how this can affect its meaning. The framework of the semantic description was laid through the comparison of the definitions of these words from several major dictionaries. This framework is refined through the use of the online corpus collection: Corpus of Contemporary American English (COCA). Many samples of each word have been collected, and the collocations stemmed from the concordances lines were examined to ascertain different shades of meaning.
\end{abstract}

Keywords: Semantic, Analysis, Corpus, COCA

\section{Introduction}

Synonymy can be defined as a word that has the same meaning or nearly the same in one or more senses as another word (Saeed, 2003). Despite the closeness and the sameness of synonyms, they have subtle distinguished meanings that cannot be substituted with other words (Edmonds \& Hirst, 2002). For example, even though the words untruth, lie, falsehood, fib and misrepresentation are near-synonyms and they denote a notion that does not conform to "truth", they are still different from each other in some aspects of their meanings (Saeed, 2003). The word misrepresentation denotes a direct and deliberate deviation from truth whereas the word lie implies a deliberate and direct action. Similarly, the word fib is also an intentional falsification but it is used and fabricated to save face. As for the word untruth, it is sometimes told out of ignorance and is not used to deceive people.

Leonard Bloomfield (1984, p.145) states that "if the forms are phonemically different, we suppose that their meanings also are different - for instance- that each one of a set of forms like quick, fast, swift, rapid, speedy differs from all the others in some constant and conventional feature of meaning." As can be interpreted from this statement, meanings tend to restrict themselves to specific areas of context and usage as well as specific collocational knowledge.

There are few studies on synonymy although synonyms are of paramount importance. Differentiating between synonyms is vital for recognizing words depth knowledge (e.g. their real contexts, registers, collocations). Additionally, acquiring synonymy is an important skill in learning another language. One 
of the most significant studies on synonyms was conducted by Martin (1984) who found that damage, for instance, takes an inanimate object whereas injure takes an animate object.

Kayaoglu (2013, p.130) says "one challenging issue for non-native speakers of English is to decide the right word for a particular register in which language behaves differently." He adds that mono or bilingual dictionaries usually fail to provide comprehensive information about the use of words in different registers. He believes that with the help of corpus analysis, one can make judgment about words and their real registers as well as their collocates. A corpus provides synchronous insights into language use while dictionaries or other books fail to be as dynamic as corpora and language resources.

The aim of this paper is, firstly, to examine the dictionary definitions of these six words to form a basic understanding of their usage and senses. Secondly, it is to compare the definitions with the COCA concordance which will enable us to have these words in the actual contexts. The attempt is to find a pattern of some sort to know how these words are used in contexts and what kind of registers they are.

\section{Methodology}

The purpose of this paper is to use a corpus-based analysis to show the differences and similarities between six closely related words: babble, blather, chatter, gibber and jabber. These six words all appear as several different lexical types, but this paper will focus on their adjectival, verbal and noun usage. The distribution of these words across five registers - Spoken, Fiction, Magazine, Newspaper and Academic - will also be looked at in some detail. Finally, the usage of these words through the temporal dimension will be examined and the results will determine whether usage is increasing or decreasing.

Two of the words that are examined, chatter and prattle, also have the related verb forms chat and prate. These verb forms are not incorporated into the scope of this paper. The reasoning behind the omission is that prate only has 16 instances in COCA, a corpus of over million words. The data selection is too small to allow any real analysis of the differences between the two forms prate and prattle. As for the verb chat, a cursory examination showed that the sense of this verb as compared to that of chatter is completely different. The word chatter almost always refers to foolish talking, or inanimate repetitive sounds, whereas chat refers more to an intimate act of talking among friends. There is, however, another nuance of meaning between chat and chatter with reference to the internet culture. The word chat, as a verb, refers to the action of instant messaging and chatter is the noun that refers to the content of those messages. Because of these reasons, it is decided to abstain from further in depth examination of these two words.

\section{Semantic Analysis}

We start by looking up the connotations of the six remaining words at first. Two dictionaries are exploited: The Oxford American Dictionary of Current English (2006) and The Random House Dictionary (2009). In Table 1, The Oxford American Dictionary of Current English, glosses the six studied words in terms of chatter and chooses not define the different lexical types of the words. 
Table 1: The Oxford American Dictionary of Current English

\begin{tabular}{|l|l|}
\hline Babble & $(\mathrm{V}),(\mathrm{N})$ Talk in an incoherent manner. Chatter excessively. \\
\hline Blather & $(\mathrm{V}),(\mathrm{N})$ Foolish chatter. \\
\hline Chatter & $(\mathrm{V}),(\mathrm{N})$ Talk quickly, incessantly, trivially or indiscreetly. \\
\hline Gibber & $(\mathrm{V}),(\mathrm{N})$ Chatter volubly and incoherently. \\
\hline Jabber & $(\mathrm{V}),(\mathrm{N})$ Chatter or say in a childish or inconsequential way. \\
\hline Prattle & $(\mathrm{V}),(\mathrm{N})$ Chatter incoherently. \\
\hline
\end{tabular}

Table 2, The Random House Dictionary (2009), is more accurate in that it defines the separate verbal and noun usages of the words. However, it still maintains the habit of using the words to define one another.

Table 2: The Random House Dictionary

\begin{tabular}{|l|l|l|}
\hline Babble & $\begin{array}{l}\text { (V) to utter words imperfectly, indistinctly or } \\
\text { without meaning: to talk idly, irrationally, } \\
\text { excessively or foolishly chatter or prattle. }\end{array}$ & $\begin{array}{l}\text { (N) Inarticulate or imperfect } \\
\text { speech; foolish, meaningless or } \\
\text { incoherent speech; prattle. }\end{array}$ \\
\hline Blather & (V) To talk or utter foolishly; blither, babble & (N) Foolish, voluble talk. \\
\hline chatter & $\begin{array}{l}\text { (V) To talk rapidly in a foolish or purposeless way; } \\
\text { jabber. }\end{array}$ & (N) Purposeless or foolish talk. \\
\hline Gibber & $\begin{array}{l}\text { (V) To speak inarticulately or meaninglessly; to } \\
\text { speak foolishly; chatter }\end{array}$ & (N) Gibbering utterance \\
\hline Jabber & $\begin{array}{l}\text { (V) To talk or utter rapidly, indistinctly, } \\
\text { incoherently or nonsensically; chatter. }\end{array}$ & $\begin{array}{l}\text { (N) Rapid indistinct or } \\
\text { nonsensical talk, gibberish. }\end{array}$ \\
\hline Prattle & $\begin{array}{l}\text { (V) To talk in a foolish or simple-minded way; } \\
\text { chatter, babble. }\end{array}$ & $\begin{array}{l}\text { (N) The act of prattling; } \\
\text { chatter, babble. }\end{array}$ \\
\hline
\end{tabular}

Upon checking various major thesauri, all the studied words seem to be listed as synonyms of each other, although the two major synonyms are babble and chatter. While sometimes the other words would be present or not, these two are always prominent in the synonym list.

While the definitions of the words do differ somewhat, they all contain the same element of foolishness, and most have something related to rapidity. Some distinctions of meaning are foreshadowed in that jabber and babble seem to connote difficulties in the physical act of speaking, while the rest seem to show excessive ease in speaking or the want of awareness towards what is said.

The Figure 1 below shows the total number of occurrences of words. When viewed with the awareness of the similarity of all the words primary definitions, it is a bit surprising that chatter has more than double the occurrences of all the others. 


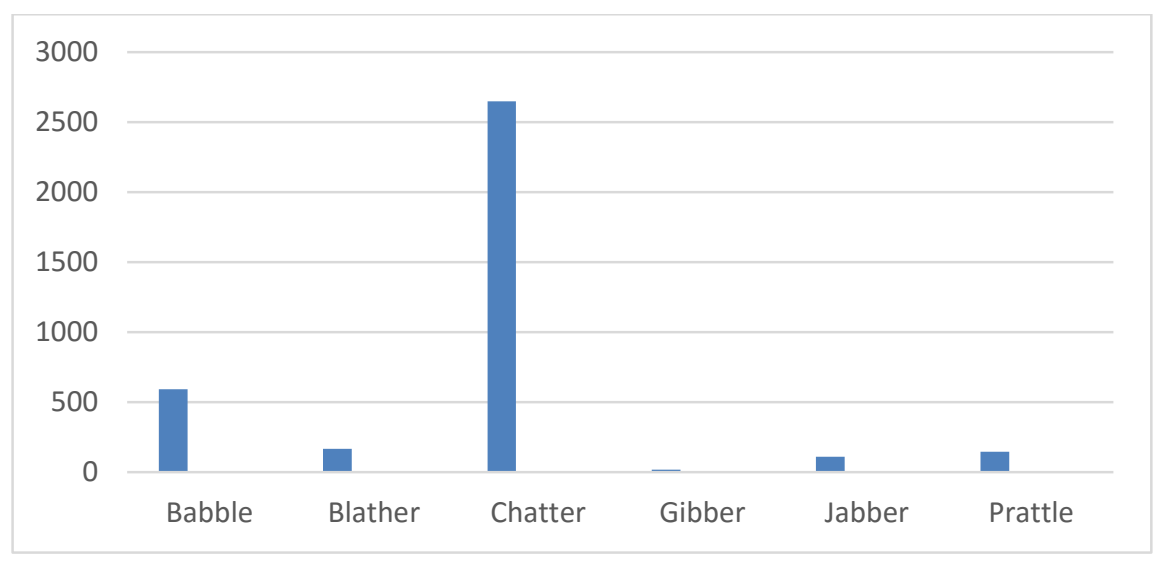

Figure 1: The total number of occurrences of the target words

All six of the words occur in all of the registers of the corpus that are examined, as illustrated in Table 3 and Figure 2.

Table 3: Number of occurrences of the target words in different genres

\begin{tabular}{|l|c|c|c|c|c|c|}
\hline \multicolumn{1}{|c|}{ Register } & Babble & Blather & Chatter & Gibber & Jabber & Prattle \\
\hline Spoken & $6 \%$ & $8 \%$ & $8 \%$ & $3 \%$ & $3 \%$ & $4 \%$ \\
\hline Fiction & $62 \%$ & $41 \%$ & $56 \%$ & $69 \%$ & $69 \%$ & $67 \%$ \\
\hline Magazine & $16 \%$ & $24 \%$ & $19 \%$ & $22 \%$ & $15 \%$ & $14 \%$ \\
\hline Newspaper & $8 \%$ & $22 \%$ & $13 \%$ & $6 \%$ & $13 \%$ & $10 \%$ \\
\hline Academic & $8 \%$ & $5 \%$ & $6 \%$ & $0 \%$ & $2 \%$ & $5 \%$ \\
\hline
\end{tabular}




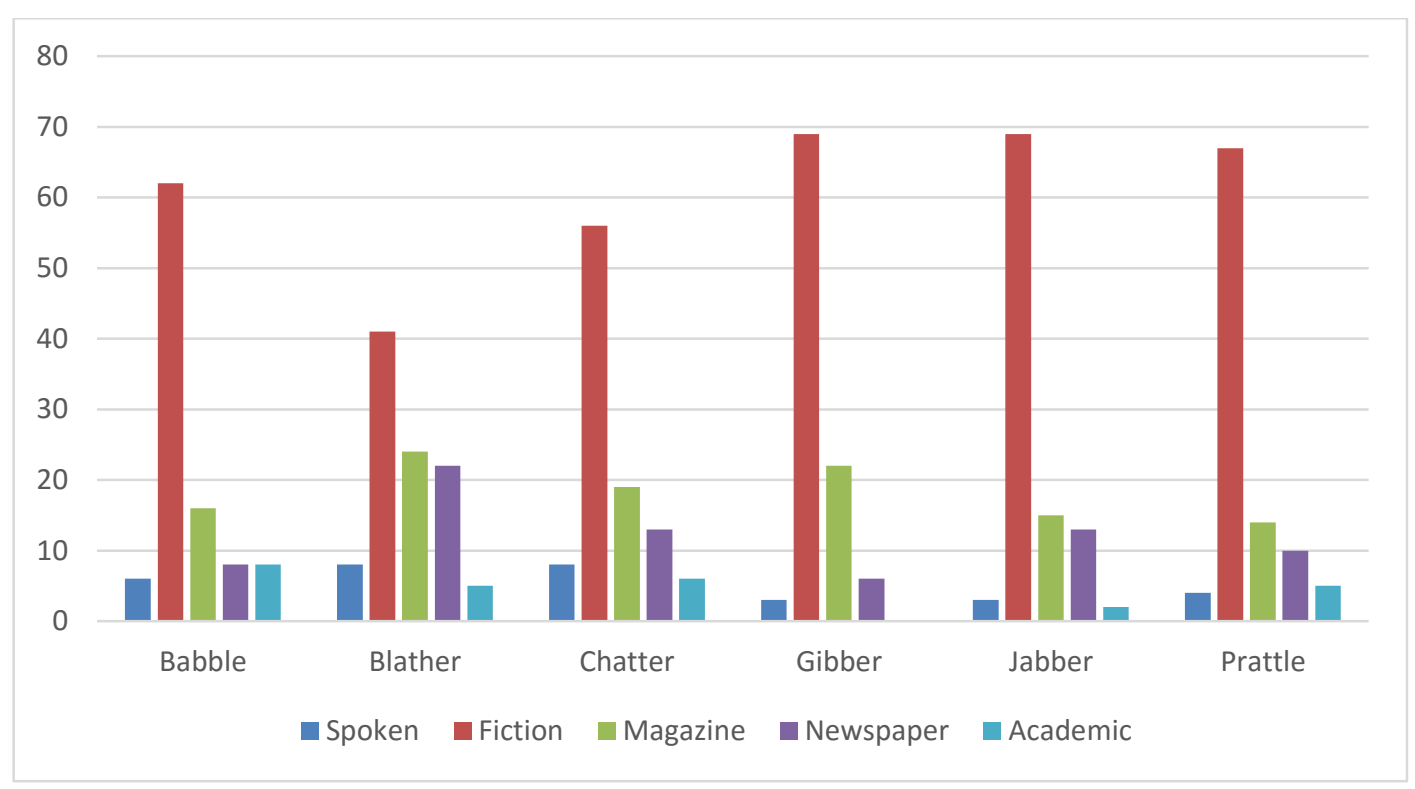

Figure 2: Number of occurrences of the target words in different genres

The fact that all of the words have the most occurences in fiction is not a surprise given the fact that authors usually narrate their stories with details. However, it is interesting that babble has the most instances of academic usage, at least comparatively speaking. This seems to be because of the interest that psychologists have in the babble pre-linguistic children produce.

(1) a. While infants make sounds and babble, they do not use true expressive language until they have understood words.

The register that comes in next with the largest quantity of overall usage is Magazine, which is again, not very surprising as they often have fictional elements. Masgazine is closely followed by Newspaper, which makes sense because of the imagery available in these words. What is a bit unexpected is the small presence of these words in the spoken register. None of the words has much of a presence there which leads to the belief that they all serve a more literary function, or that perhaps they serve more to create an image than to express a meaning.

Another fascinating thing of note is that blather has the greatest presence in the Newspaper and Magazine registers as compared to the other words. It is also interesting to note that the pair of words blather and chatter, and jabber and prattle show similar distribution patterns across the registers.

Finally, there are some things of note in the number of usages of these words across time. Although this corpus only covers a span of 28 years, it is significant that there are already visible trends in the decline or increase of these words. Figure 3 shows the general trends. 


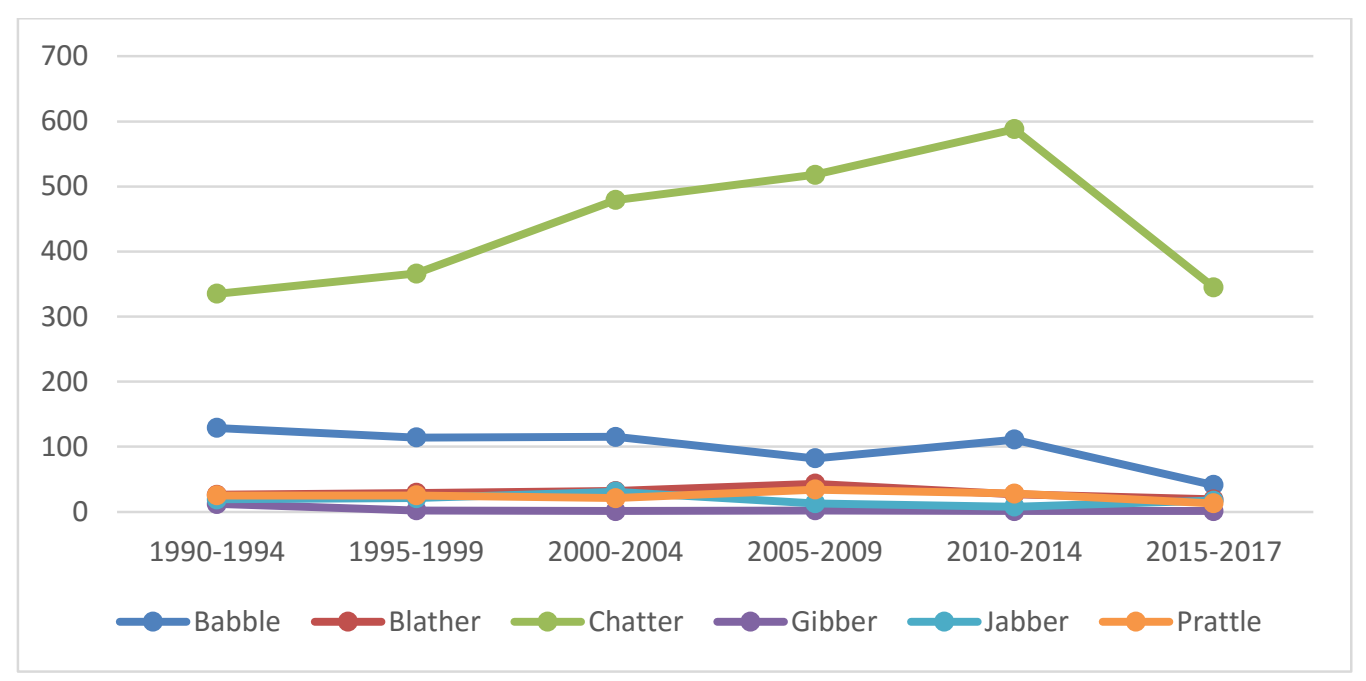

Figure 3: Temporal Dimension

The frequency of these words throughout the two decades has not been greatly affected. However, there is an increase in usage of chatter from 1990 - 2014, but it declined in 2015.

\subsection{Target Words across Noun, Verbal and Adjectival Usage}

All of the words cross the three different lexical categories of Noun, verbal and adjectival usages as is seen in Table 4.

Table 4: The target words cross different lexical categories

\begin{tabular}{|l|c|c|c|c|c|c|}
\hline & Babble & Blather & Chatter & Gibber & Jabber & Prattle \\
\hline Noun & $29 \%$ & $62 \%$ & $48 \%$ & $8 \%$ & $19 \%$ & $31 \%$ \\
\hline Adjectival & $8 \%$ & $1 \%$ & $7 \%$ & $18 \%$ & $9 \%$ & $3 \%$ \\
\hline Verbal & $63 \%$ & $38 \%$ & $45 \%$ & $74 \%$ & $75 \%$ & $66 \%$ \\
\hline
\end{tabular}

It is interesting that three out of six of the words babble, gibber, jabber and prattle occur predominantly in their verbal form and that only one has a prominent appearance in its adjectival form (Gibber). Only chatter and blather occur primarily in their noun form. Another difference is that of gibber, which follows the pattern of predominant verb usage, but changes in that the adjectival usage is secondary. In fact, it has an appearance as a noun in few instances. For this reason, gibber will be omitted from further in-depth examination in the noun category.

\subsubsection{Noun Usage}

Simply looking at the distribution of these words in their noun usage across the registers yields some interesting patterns as shown in Table 5. 
Table 5: The noun-phrase usage of the target words across various registers

\begin{tabular}{|l|c|c|c|c|c|}
\hline Noun usage & Babble & Blather & Chatter & Jabber & Prattle \\
\hline Spoken & $8 \%$ & $9 \%$ & $12 \%$ & $4 \%$ & $8 \%$ \\
\hline Fiction & $53 \%$ & $32 \%$ & $43 \%$ & $42 \%$ & $62 \%$ \\
\hline Magazine & $15 \%$ & $25 \%$ & $21 \%$ & $20 \%$ & $14 \%$ \\
\hline Newspaper & $12 \%$ & $30 \%$ & $17 \%$ & $28 \%$ & $8 \%$ \\
\hline Academic & $12 \%$ & $5 \%$ & $7 \%$ & $26 \%$ & $8 \%$ \\
\hline
\end{tabular}

They appear more in the fiction, magazine and newspaper registers. The word chatter is rather interesting in that it has three separate meanings that are almost equally predominant. There is what may be taken as the "original meaning", which is the aural perception of voices combing to make a sound.

(2) a. Rather than expressing convivial chatter around a holiday table .....

b. When they finish, the buzz of pre-meeting chatter subsides....

There is another meaning that describes a sound that is very distinct from the oral production. The word chatter is used to represent the recordings of foreign nationals that the U.S. government monitories for terrorist activity.

(3) a. ... Jones monitored the radio chatter of tour boats...

b. Robert said intelligence analysts had picked up some disturbing terrorist chatter.

This usage is so predominant that one of the top three collocations of chatter in its noun form is "radio".

The final meaning of chatter as a noun is two-fold. It can be the written expression and opinions of the higher-middle class on perceived social problems. It can also be written conversations that are either about social problems or just inconsequential nothings that are often found in internet chat rooms.

(4) a. Talk shows, letters to the editor and online chatter analysed, scrutinized and, more often than not, criticized.

b. Noticed a lot of continued chatter on the previous blog about the ongoing struggles of Andruw Jones...

c. .... There's just something about the genre that elicits much Washington chatter at the expense of actual Washington reading.

These three separate, yet related, usages of chatter are very intriguing, especially in consideration of Figure 3. The word chatter is nearly the one word that has had rather remarkable growth in usage. It is easy to hypothesize that the cause of the increase that started in 1995 and continues is the growth of the internet culture, especially in the blogging sense. It is unfortunate that COCA only extends back twentyeight years. It would be fascinating to see if there was an earlier jump of usage that correlated with the advent of radio espionage after World War II and during the time of the Cold War. It is also possible that there was an increase simply because of the intervention of the radio itself. It would be an interesting topic of research just to focus on the word chatter itself and how it has grown in meaning throughout time and if those changes correlate with major historical changes. Unfortunately, this line of inquiry is a bit beyond the scope of the current research. 
The word blather is interesting in that it differs from chatter and babble in that it only refers to speaking, or to the opinion of someone, and not to a sound. The other interesting difference is that blather is often setoff as being produced by a specific group. It is most often used as a derogative term towards the ideas that a certain group holds.

(5) a. Keep all this in kind as the elections approach and the political blather increases.

b. ... Magdalene, while pundits in the secular press ridicule her spirituality as flaky New Age blather.

As for Jabber, it is fascinating that its noun form is nearly indistinguishable from the oral form of chatter. The word jabber is also the only word that seems to relate to radios as well.

(6) a. She ignored his jabber and concentrated on Pan, if "concentrated" is the accurate verb.

b. ... it's a realm of computer-simulated jabber.

c. ... and arguing over a game of cards set out on the ground, and the jabber from their radio?

It is noticeable that chatter can be substituted for jabber without any loss of meaning in all of these examples. Indeed, chatter can be substituted for nearly all usages of jabber in the contexts found on COCA without suffering any loss of meaning or connotation. While jabber can almost universally be replaced with chatter, it is not true of the reciprocal. This is a very interesting pattern because it suggests that chatter is a true synonym of jabber, whereas jabber is only sometimes a true synonym of chatter. While in some instances this is obvious, such as the visual meanings of chatter as written communication, it's very interesting that jabber cannot be substituted for chatter even when they are both representing orally produced phenomena.

(7) a. The chatter soon turned to the thin ice, and one of the drivers said he had ....

b. She cannot stand his cloddish everyday chatter, concluding irrevocably that's he does not know this man she once married ....

c. the rehearsal hall, busy with chatter and movement five minutes before, had grown very still.

In these three contexts, for example, jabber can only be switched for chatter in the (b) example. In the other two contexts, substituting jabber detracts some of the meaning, or rather adds in some subtle connotations of childishness and lack of meaning. Especially in the first example the use of jabber would be extremely odd. It is almost as if the word jabber is not capable of supporting a subject of such import as thin ice.

The word Prattle is similar to blather in that it also is generally specific to a subject, or to a specific group. However, it is set apart even more as being produced by a single person.

(8) a. ... testers regularly find that temp ratings are about as reliable as a used-car salesman's prattle.

b. I found it difficult to listen to Glume's prattle ...

This focus on individuals makes prattle unique from a noun among all the other words. It is usually used in context with the inconsequential speech of only one person and in this focused usage refers specifically to the act of speaking itself.

Babble, when used as a noun, does not seem to refer to the act of speaking so much as it does the combination of many voices to make an overarching sound. 
(9) a. A shout pierced the crowd's babble . "I am guily!"

b. ... conference room crowded with reporters and HD cameras. There was the usual babble of shouted questions

The combination of many sounds into one seems to be more common in usage than the reference to the manner of speaking. This is in direct contradiction to the major definitions found in dictionaries. Also, a sizable portion of the appearances of babble is joined with reference to a large group such as "crowd", a "crowded with reporters" etc. Chatter seems to be more distinct and on a lesser aural level than babble such as a dinner party or a meeting group.

\subsubsection{Adjectival Usage}

Simply looking at the distribution of these words across the registers yields some interesting patterns as shown in Table 6.

Table 6: The adjectival-phrase usage of the target words across various registers

\begin{tabular}{|l|l|l|l|l|l|l|}
\hline $\begin{array}{l}\text { Adjectival } \\
\text { Usage }\end{array}$ & Babble & Blather & Chatter & Gibber & Jabber & Prattle \\
\hline Spoken & $11 \%$ & - & $2 \%$ & $14 \%$ & - & $14 \%$ \\
\hline Fiction & $55 \%$ & $100 \%$ & $73 \%$ & $64 \%$ & $58 \%$ & $43 \%$ \\
\hline Magazine & $20 \%$ & - & $12 \%$ & $22 \%$ & $26 \%$ & $14 \%$ \\
\hline Newspaper & $5 \%$ & - & $10 \%$ & - & $11 \%$ & - \\
\hline Academic & $9 \%$ & - & $3 \%$ & - & $5 \%$ & $29 \%$ \\
\hline
\end{tabular}

The words chatter and blather in the noun sense, which have the overall highest number of usages in the spoken register, either do not appear at all in an adjectival usage, or barely appear. It is also worthy of note that the only time that gibber appears at all in the spoken register, is when it is in its adjectival form.

A fascinating insight that arose from this research is that the words are all much more closely related to each other in their adjectival form than they are in their noun form. For example, blather only has four instances of adjectival usage and in all four instances can be replaced with prattle without any loss of meaning.

(10) a. Soon, in the blathering small talk that kills time, ED Myers and Dary Jordan identified a bond beyond.

b. Their remarks are meant to catch you off-guard, so you turn into a blathering idiot.

The only distinctions about it as an adjective is that it is slightly more derogatory than prattling. However, this seems to come about because its use is more marked.

Chatter adds yet another meaning to its already formidable collection. Besides being used to represent a continuous stream of sound, it is most often used to illustrate a sort of rattling sound. Chatter is the only word of the set that can refer to inanimate objects, other than water, and does so quite often.

(11) a. The soldiers fired on the ghostly forms, but no blood was spilled by the chattering weapons. 
Chatter most commonly appears as part of the idiom " chattering teeth" which appears astonishing 212 times.

(12) a. " Oh, please!" she managed through chattering teeth. "please".

When it is used with animate things, it is either illustrating the sound a squirrel makes or it is used od people speaking quickly and incessantly.

(13) a. .... The chattering chrr od a scolding red squirrel.

b. They stopped at a crossroads, and a band of chattering children climbed on.

There is another and final usage of chatter as an adjective, and this one is rather puzzling.

(14) a. "There was no criticism from the press and the chattering class of coming back with Rezko ad."

b. How dare Michael Elliot refer to " the chattering classes of London" who think of Blair as smug.

This term " chattering class" was originally British and came into existence in 1980s and refers to members of the super class commenting on current issues. It is interesting because this usage is increasing, although it is still minor and only occurred 55 out of 1783 times. It is puzzling as to why chattering does not deserve a separate entry as an adjective when the adjectival form carries a meaning that the noun and verbal form does not.

The relation between jabber and chatter can be seen here is that jabber seems jabber seems to heighten an impression of loudness more than chatter. There is however an interesting exception, jabber can only refer to people speaking and it does not have the rattling connotation.

Babble as an adjective has a strong association with water because of the collocation "babbling brook"; nearly $40 \%$ of the uses of the adjective have a collocation with water. In its adjectival form, it more commonly refers to speech than to the overarching sound that is the norm for the noun phrase. However, it seems to be produced by individuals and seems to mean speaking quickly.

(15) a. We sipped wine and counted stars from a patio overlooking a babbling brook at the Denali Princess.

b. From her babbling monolog, apparently Mathilda knew Darcy from his pub days.

c. .... Try to cultivate a clever heart before you get yourself into trouble" Babbling apologies, Khawi scurried away.

As for prattle and gibber, prattle does not have any occurrences, only 7, and is primarily derogatory. Those who prattle are self-proclaimed pundit whose speech is looked at with disgust by those who are knowledgeable.

(16) a. Georgia, takes aim at: Jeff Smith, Public Television's prattling peacenik Frugal Gourmet.

b. But Jane could not at once think of any remark sufficiently prattling and artless to make a beginning with. 
Gibber is quite different from the rest in that it is primarily found in collaboration with the ideas of terror, fear, and madness. It has a rather circular relationship with terror because gibbering is a result of being afraid, but being surrounded by gibbering beings also seems to inspire fear.

(17) a. The deserter had been reduced to a gibbering mass, a once powerful man stripped of his strength by the cruelty of Fargo...

b. I will be infected with the pilot's helplessness, his gibbering fear.

c. The terrible jungle and gibbering noises again.

d. You may become what you like, a king or a gibbering madman.

\subsubsection{Verbal Usage}

Generally speaking, there are not many differences between the verbal usages and the adjectival usages of these six words. Perhaps this is the reason why dictionaries do not separate the entries.

When used as a verb, chatter maintains all of the same meanings that it has as a noun and an adjective. It still represents a continuous stream of speech that is generally produced by a small group or an individual. It still appears as a clattering sound with teeth and guns and the conversational aspect is still generally looked down on as rather insignificant. A final note on chatter is that it often has another type of collocate, which is a preposition such as away which implies an extended continuation of the activity. The collocate teeth co-occur with chatter 174 and away 84 times.

Prattle as a verb can be linked back to its noun meaning in that it is generally inconsequential, never ending and a drone of continuous sound, all of which are produced by only one person.

(18) a. Portentia used a crystal ball and prattled a lot of mumbo jumbo...

In the verbal usage, it is easier to see that babbling tends to be difficult to understand for the listener. When someone is babbling, they are generally slurring and not making much sense.

(19) a. I babbled something that ended in yes, then headed for the bathroom.

b. she babbled on some more, waving at the mat, but he got the gist of it.

Babble is additionally commonly used in the sounds that babies make before they could speak.

(20) a. The baby babbled while playing in her crib.

Babble could also mean telling a secret or private information without being conscious of that.

(21) a. She babbled the whole surprise party plan to me without a thought.

A final intriguing note on babble is what happens when it is compared to gibber. For all that babble can be insignificant and difficult to understand, it is still speaking, engaging in communication, but gibbering is not even considered to be that high. It is merely uttering sounds in fear.

(22) a. He knew he was babbling but if he stopped talking he'd probably start gibbering in fear... 
With blather there was only one interesting connotation: it can apparently be used as an avoidance of an uncomfortable subject. People tend to blather on about something unimportant, rather than addressing what is truly on their minds.

(23) a. What he did remember was the brisk voice that said, "Sir Malcolm", by way of greeting. It was already midmorning across the pond. For his special friend to call him at that hour had to mean something very serious was wrong somewhere, and somehow it affected either him or the sisters. Somehow Charles managed to find his voice. Tell me straight off, Bess. "he took a second to wonder why he was calling his friend "Bess". Normally he called her "Liz" Bess was reserved for times of crisis. "Don't blather on. I can take it, whatever it is."

There is however a couple of nuances of meaning that are not present in other words. Jabbering tends to take place amongst a group, and this group is using their unique jargon, which expresses their cohesiveness. This jargon is incompressible to those outside of their group. To use a comparison, chatterers do not care who is listening to them, or who is overhearing, nor do babblers, but sometimes people jabber to establish themselves as a group.

(24) a. A group of aliens at the far side of the room were jabbering at each other and throwing switches.

\section{Conclusion}

Some interesting patterns have begun to emerge in the examination of the corpus data as compared to the dictionary data. The six words that are chosen have a primary definition of oral communication that has something to do with rapidity and nonsense. They mostly occur in fiction and newspapers followed by magazines. Chatter and babble are the most common words among the target synonyms. Gibber, Jabber and prattle are not used frequently as chatter and babble. Jabber and babble connote difficulties in the physical act of speaking. Jabber and babble seem a bit louder than chatter. Generally speaking, the target words show differences in their verbal, noun ad adjectival usages. Babble has a strong association with water. Gibber, on the other hand, strongly correlates with the ideas of terror, fear and madness. Chatter appears most with the rattling sound or as part of the idiom "chattering teeth".

\section{References}

Bloomfield, L. (1984). Language. Chicago: University of Chicago Press.

Corpus of Contemporary American English (COCA). Retrieved from https://www.englishcorpora.org/coca/

Edmonds, P., \& Hirst, G. (2002). Near-synonymy and lexical choice. Computational Linguistics, 28 (2), 105-144.

Kayaoglu, M. (2013). The use of corpus for close synonyms. The Journal of Language and Linguistic Studies, 9 (1), 128-144.

Martin, M. (1984). Advanced Vocabulary Learning. The case of synonyms. Modern Language Journal, 86, 130-137.

Saeed, J. (2003). Semantics. Oxford: Wiley Blackwell. The Oxford American Dictionary of Current English (2006).

The Random House Dictionary (2009). Retrieved from http://dictionary.reference.com/browse 